\title{
THE IMPACT OF DENSITY AND SCALE ON THE LIFE CYCLE COST OF NET ZERO ENERGY COMMUNITIES
}

\author{
Slava Shubin, Gad Rabinowitz, and Shabtai Isaac \\ Ben-Gurion University of the Negev, Beer-Sheva, Israel
}

\begin{abstract}
It is widely agreed that expanding the Net Zero Energy concept to a community scale brings multiple advantages in terms of design flexibility, cost reduction, clean energy and resource management. However, it is less clear what the scale or the density of the community should be to utilize these advantages in the best possible way. The objective of this work is to study how the Life Cycle Costs of new Net Zero Energy communities are affected by changes in their density and scale. To achieve this objective, a model was developed for identifying the optimal configuration of energy technologies for each specific scale and density. The analysis takes into consideration the local climate and the types of buildings in the community. The results of the implementation of the model show that both urban density and scale have a direct impact on the costs of NZE communities, but in ways that depend on the local climate.
\end{abstract}

\section{Introduction}

A Net Zero Energy (NZE) building is one that combines energy efficiency and renewable energy utilization to reach a balanced energy budget over a yearly cycle (Voss, Musall, \& Lichtmeß, 2011). To date, a standard definition or protocol of NZE buildings has not yet been defined, as the system's boundaries, scope and balance calculation methods differ between projects and countries. In this study, the concept of a NZE community was studied - a community that has reduced energy needs, so that the balance of energy requirements within the community is met by renewable energy (Carlisle, Geet, \& Pless 2009).

The following categories of technologies are typically incorporated in NZE communities:

- High-efficiency building envelope components and Heating, ventilation, and air conditioning (HVAC) systems that will reduce the consumption to a minimum.

- Renewable Energy Systems to supply the remaining demand for energy from renewable sources, integrated at a building and/or at a community level.

- Energy management systems at building and community levels for optimizing the distribution and utilization of energy.

The enlargement of NZE concept to a community scale encompasses a number of potential advantages for the incorporated technologies:

- Centralized and high demand for certain components or technologies allows to utilize the economies of scale.

- The requirement to achieve the NZE balance on a community rather than on a building scale allows the consideration of a larger variety of building forms, styles and building integrated (BI) technologies.

- The energy resources can be managed at a community level and shared between the buildings.

- The possibility to install technologies at a community level enables the consideration of multi-building systems, such as commercial Photo-Voltaic (PV) installations or bio fueled district heating centers. These systems can be installed on large structures such as parking facilities and commercial buildings, or in other available areas in the community.

Such multi-building systems have several advantages, including centralized maintenance, shared energy management and peak thermal load diversity - the simultaneous heating/cooling peak load of multiple buildings together is smaller than the sum of all individual building peak loads (DeBaillie 2012). Expanding the NZE concept to a community scale thus brings multiple advantages in terms of design flexibility, cost reduction, energy and resource management. However, it is less clear what the scale or the density of the community should be to utilize these advantages in the best possible way. In particular, it is not clear how the energy related costs of such a community can be minimized.

\section{Literature review}

There are many papers discussing and analyzing the design and implementation of energy production/ reduction/ management systems in NZE neighborhoods. Marique \& Reiter (2014) analyzed the implementation of the NZE concept at a community scale focusing on two aspects: (a) the impact of urban form on building energy requirements and the required capacity to supply it using on-site renewable energy production; (b) the effect of location on energy consumption for urban mobility. The study suggests that these aspects must be considered in an integrated manner in the design of NZE communities. Orehounig, Evins, \& Dorer (2015) describe a method of integrating decentralized energy systems at a neighborhood scale. The method is based on the "energy 
hub" concept by which the input and output energy flows are managed in order to optimize net energy consumption. A review of such modelling approaches, focusing on analytical tools for integrating energy systems at the district level while considering both building and urban scale aspects was given by Allegrini et al. (2015).

The intensive initial investments in the technologies that are later compensated by savings in operational costs of the building make the Life Cycle Cost (LCC) analysis an effective technique to evaluate and compare the economic feasibility of NZE buildings. Fuller \& Petersen (1996) describe the LCC analysis as a structured approach to consider all the potential costs of a 'project' in a given period of time, including adjustments to reflect the value of money over time. The approach allows the identification of the most cost-optimal alternative among others once the LCC of all alternatives is analyzed under the same economic assumptions and service life time. The specific costs that the LCC of a project/product/system encompass can vary according to product type, industry, complexity and ownership model, but can always be summarized by the following three types:

1. Initial investment costs - the initial cost includes all the potential costs of a system before it was put into operation. It may include designing, planning, construction, acquisition, supply, assembly costs, etc.

2. Operational and Maintenance costs - these costs are all the potential cost of a system after it was put into operation. It may include energy costs, spare parts and labor required for maintenance - whether scheduled or due to failures, and in general all costs that appear from the first service date of the system and until its end of service life.

3. End of Life cost - these costs appear at the end of life of the system and may include its disassembly, demolition, recycling, and all the required costs needed to take the system out of service.

To consider the value of money over time the LCC is to be calculated in present value terms, which requires to discount all future costs to its equivalent present value, considering the interest rate and inflation in market.

The objective of the LCC analysis/optimization is to examine the feasibility of the whole project, therefore, the analysis will deliberately neglect the investment/income distribution among the stake holders. The capital distribution topic is typically addressed by business models, which are typically set before the LCC analysis/optimization is performed.

LCC analysis and design optimization of NZE buildings is widely covered by multiple researches, in different countries and climate zones (Hamdy et al. 2011; Marszal \& Heiselberg, 2011; Marszal et al. 2012; Moran, Goggins, \& Hajdukiewicz, 2017; Zakis, Zakis, \& Arfridsson, 2016). However, LCC analysis of NZE neighborhoods has been discussed much less, probably due to their novelty and very few real-life implementations of the concept. It is expected that compared to a single NZE building, the previously described advantages of NZE communities will have a positive impact on the LCC of the technological design. Consequently, the following questions arise:

1. How does the LCC change due to the enlargement of NZE concept from a single building to a community?

2. How does the scale, i.e. the number of buildings in a NZE community, affect the LCC?

3. How is the LCC affected by the density of the community and by the area available for the implementation of multi-building systems?

\section{A model for identifying the optimal design of NZE settlements}

The technological design of NZE communities is complex for the following reasons:

1. Multiple types of technologies that are interacting with each other are to be considered to effectively achieve the NZE balance

2. While some technologies perform better when installed at the building level, others perform better when installed at a community level. The cost-optimal level of implementation highly depends on the type of technology, the urban form of the community and the cost of land.

3. A bigger size of technologies is usually related to lower costs. However, in NZE communities most of the technologies are implemented inside the community, as part of the urban fabric. Therefore, large-scale technologies that are believed to be more cost effective may be unfeasible or eventually too costly to implement in NZE communities.

4. The same urban density may have a different impact on the cost and energy performance of different technologies. One example is heat distribution systems that perform better in dense areas vs. solar energy based technologies that require some space to reach the needed solar irradiation.

The objective of this research is to analyze how the LCC of new NZE communities are affected by changes in their density and scale, and what these should be in order to utilize the advantages of such communities in the best possible way. The results of this study could lead to a better understanding of the implications of NZE requirements for urban planning. Unlike a single NZE building where the technological design is set according to a given urban environment, the urban form of a NZE community is a variable that can be altered in the design phase and have huge impact on the energy and cost performance of the community. A precise urban form of NZE community will help to achieve cost-optimal technological design, high energy performance and the required cost reduction for a wide adoption of this concept.

\section{Optimization model}

To achieve this objective, a generic and comprehensive LCC optimization model was developed with which the optimal configuration of energy related technologies can be identified for each specific urban scale and density, while taking into consideration the local climate and the type of buildings in the settlement. This model can be used 
as a tool to study the implications of NZE requirements for urban planning.

The optimization model was developed under the simplifying assumptions that all the buildings in the community are similar in shape, energy demands and potential of renewable energy production on rooftops. In addition, it is assumed that the buildings are spread uniformly across the community, and that all the energy centers at a community level have the same potential of renewable energy production. Community-level energy centers can be implemented within the community, in the free area between the buildings, parking lots, rooftops of commercial buildings, etc. While these assumptions are not entirely realistic, they are not expected to significantly affect the conclusions that can be derived from the results of the implementation of the model.

In addition, it is assumed that the buildings in the studied communities are connected to the electrical grid, as are the vast majority of buildings in Europe, and that when the generated renewable energy is higher than consumption the electricity is fed into the grid according to the Net Metering regulation. An analysis of the impact of the use of renewable energy sources on the grid (in terms of variability, capacity, etc.) was not included in the scope of this study, since it focused on the settlement-scale implications of achieving NZE performance.

The objective of the model is to minimize the LCC of energy related technologies incorporated in the community, per $\mathrm{m}^{2}$ of net area of the buildings in the community. The LCC includes the initial, operational, maintenance and replacement costs in Present Value (PV) terms:

$$
\mathrm{LCC}=\mathrm{PV}(\mathrm{IC})+\mathrm{PV}(\mathrm{O} \& \mathrm{MC})+\mathrm{PV}(\mathrm{RC})
$$

IC - Initial Cost - this cost includes all the potential costs of a system before it was put into operation. It may include designing, planning, construction, acquisition, supply, assembly costs, etc.

O\&MC - Operational and Maintenance Costs - these costs are all the potential costs of a system after it was put into operation. It may include energy costs, spare parts and labor required for maintenance - whether scheduled or due to failures, and in general all costs that appear from the first service date of the system and until its end of service life.

RC - Replacement cost - in this work it's assumed that the replacement and demolition cost of a technology are equal to its initial cost. The only exception is land cost for the implementation of community integrated Renewable Energy Systems (RES) (if any). This cost will be excluded from the replacement cost because it's charged only once when initially purchased.

There are three types of decision variables in the model:

1. The inclusion or exclusion of a configuration of technologies that are required to support the regulated energy demand of the building. For example - air conditioning units for space heating and cooling with solar thermal boiler and electric back up for water heating.

2. The number of units of a building integrated system for renewable energy production of a certain type. For example - small scale wind turbines.

3. The number of units of a community integrated system for renewable energy production. For example - PV installation on a parking lot's rooftop.

The objective function is subject to the following constraints:

1. The inclusion of one configuration of HVAC \& water heating technologies in the optimal solution, to support the regulated energy demand of the building.

2. The rate of the annual regulated energy consumption of the building that must be supplied from renewable sources.

3. The available area on the rooftop of the building for effective installations of BI RES, which is changing per required energy type, i.e. solar, wind, etc.

4. The available area on the rooftop of the building for all BI RES installations.

5. The maximal allowed size of a single community energy center. It's assumed that community energy centers are integrated within the communities, therefore it can't be too big in order to fit in both functionally and esthetically. The maximum allowed area is changing according to the urban density of the community.

6. The total area of all community energy centers. The available area changes according to the urban density of the community.

The model can be easily adjusted and be subject to additional constraints according to local regulation or design decisions, e.g. capacity constraints, maximal initial cost, etc.

The implementation of the model was in Microsoft Excel software, using the Solver add-in. The model is partially nonlinear, yet smooth, both in the objective function and the constraints. Moreover, all the decision variables are Integers and Booleans, therefore the GRG (Generalized Reduced Gradient) Nonlinear Programming solving method was applied. The GRG Nonlinear method examines the gradient of the objective function as the values of the decision variables change. The method determines that an optimum solution is found when the partial derivatives are equal to zero. The disadvantage of this method is that it's highly dependent on the initial conditions and a locally optimum solution may be found instead of global optimum. To decrease the probability of this happening, a "Multistart" option was used in this study. With this option, the algorithm creates a random population of initial values that are evaluated using the GRG Nonlinear algorithm. The "Multistart" option highly increases the chance of finding a globally optimum solution (Young, 2018).

In this study, it is assumed that urban density has an impact on the following parameters: 
1. The available area for establishment of energy centers at a community level.

2. The maximal area of a single energy center.

3. The cost of land for establishment of energy centers at a community level.

A sensitivity analysis was carried out to examine the implications of variations in certain parameters (such as the available area for energy centers, the cost of land for those centers, etc.) on the LCC. However, the possible implications of future technologies and of changes in the market over time were not analyzed and are suggested as topics for further research.

\section{Application of the model}

In order to apply the model with a realistic input, data was used from two case studies that are being constructed in the framework of the "Zero Plus" project - one in Cyprus and the other in France. Zero Plus is an EU-funded project aiming to develop a comprehensive, cost-effective system for NZE communities and to implement it in a series of case studies across the EU. In order to give this research a wider perspective, the two case studies that were chosen to provide data for the model have different characteristics, and are located in different countries and climates. The assessment of the energy consumption of the buildings and of the production potential of RES incorporated in the communities is based on simulations performed with EnergyPlus software in the framework of the Zero Plus project.

The generic model that was developed is applied to optimize the technological design of the communities while changing their urban density and scale artificially. The case studies, which in reality include the construction of a limited number of buildings, were thus used as a starting point to examine the implications of an implementation of the NZE approach at a much larger scale. In order to extend the variety of technologies available for incorporation in the communities, and to reflect the impact of changes in density and scale on the cost and performance of the technologies, some of the data was collected from the literature and official reports.

\section{Cypriot case study}

The first case study that was selected is situated on the outskirts of the village of Peyia, near Paphos in the southwest region of Cyprus. The building that is considered in this case study is a high-end single-dwelling villa that is being constructed in the framework of Zero Plus Project. Cyprus has a Mediterranean climate with very mild winters and hot summers. The average annual temperature on the coast is around $24{ }^{\circ} \mathrm{C}$ during the day and $14{ }^{\circ} \mathrm{C}$ at night. Warm temperature season lasts from April to November. In the remaining period, the temperatures tend to remain mild. The scale of the Cypriot community analyzed with the model varied from 1 to 50 singledwelling buildings.

In all the examined variations in terms of scale and density, the optimal combination of technologies identified with the model includes the following technologies:
- Built-in unitary split air conditioning units of $3.5 \mathrm{~kW}$ size with heat pump version for heating and cooling.

- A solar water heating system for sanitary hot water production comprising of a 300 liters cylinder tank and 3 solar panels, with a $3 \mathrm{~kW}$ electric back-up heater, installed on the roof of the building.

- A PV system implemented at a building and/or community level with an average capacity of $12.75 \mathrm{kWp}$ per building.

All the energy consumption of the community is covered by renewable energy sources, which makes the community Net Zero Energy. However, the split between the energy produced at a building and at a community level is affected by changes in density and scale, and has a significant impact on the costs of the technologies. As the community scale (no. of buildings) and the available area for community-level energy centers increases, so does the percentage of energy produced by community integrated RES. An increase in the energy generated by the community integrated RES in turn corresponds to a lower cost in terms of $\mathrm{LCC} / \mathrm{m} 2$ (i.e. the LCC of the community divided by the net area size of the case study).

The main results in Figure 1 show that the enlargement of the available area for community-level energy centers causes an increase in the percentage of energy produced by community integrated RES, and a decrease in the $\mathrm{LCC} / \mathrm{m} 2$ of the technologies of up to $15 \%$. Moreover, the enlargement of the available area for community energy centers increases the rate at which a significant reduction of $\mathrm{LCC} / \mathrm{m} 2$ is achieved for the first time. The results are explained by the assumption that community integrated technologies are more cost efficient than buildingintegrated technologies since they share many components such as the inverter, cabling, etc. In general, the cost of PV systems decreases by $27 \%$ in larger installations (of $10 \mathrm{~kW}-2 \mathrm{MW}$ ) compared with a residential system in the range of 3-10kW (Fu et al. 2016).

The larger the area that is available for community energy centers in the community, the more community integrated systems are installed instead of BI systems, and a lower $\mathrm{LCC} / \mathrm{m} 2$ is achieved. However, the $\mathrm{LCC} / \mathrm{m} 2$ reduction is limited. The lowest $\mathrm{LCC} / \mathrm{m} 2$ is achieved when the value of the "available area" parameter is $75 \%$ (this parameter is measured using a proxy, in this case $75 \%$ of the buildings' rooftops area in the community). The enlargement of the value to $100 \%$ has no further impact since the percentage of energy produced by community integrated RES has already reached its maximal possible value of $95 \%$. The remaining $5 \%$ are produced by building-integrated solar water heating system and used for sanitary water needs. Further increase of energy production is cost inefficient due to the net metering tariff.

As presented in Figure 1, a significant $\mathrm{LCC} / \mathrm{m} 2$ reduction is achieved at a community scale at which the first energy center reaches its full possible capacity. The reason for this phenomenon is the assumption that the cost of RES per unit is decreasing as the total capacity of the installation is 
increasing. The assumption is valid for each installation by itself, which is in this case - each energy center. Further increase of scale requires the establishment of a new energy center - basically a duplication of the achieved technological design. The RES installed in the new energy center won't benefit from the reduced costs achieved in the existing energy center.

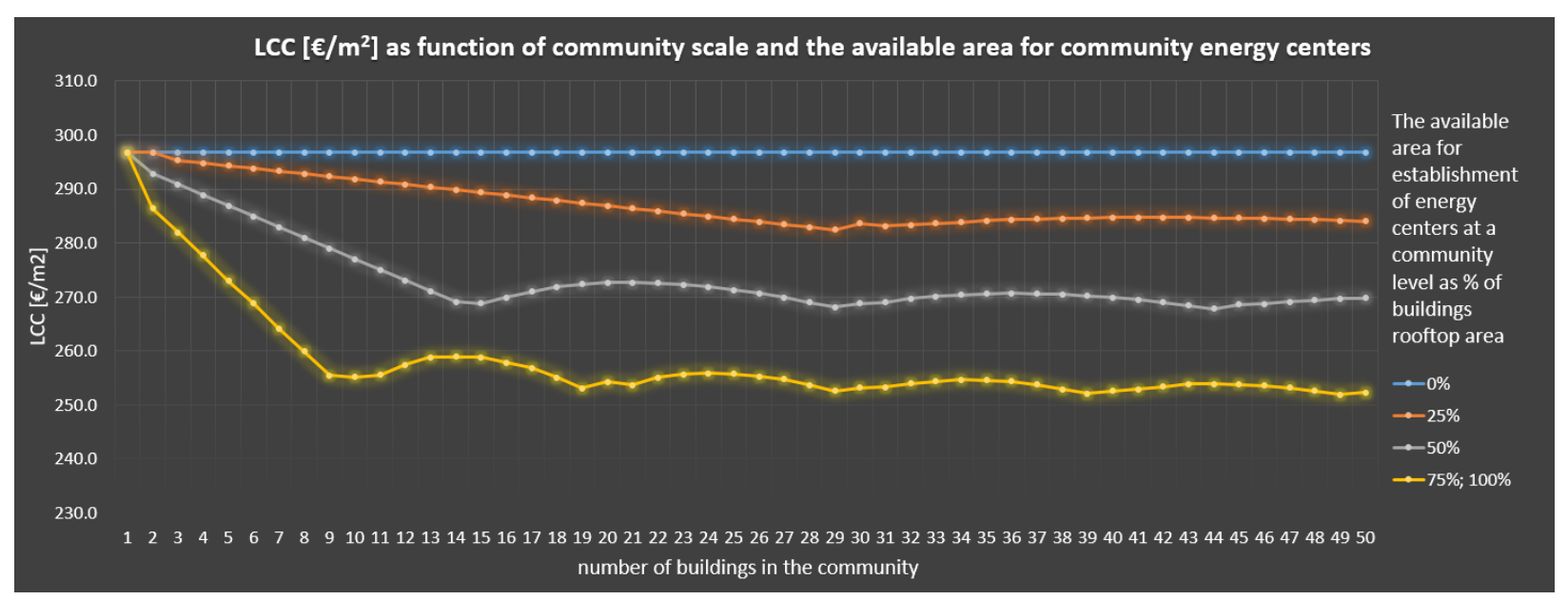

Figure 1: Cypriot Case Study, LCC/m2 as function of community scale and the available area for community energy centers

Therefore, the establishment of a new energy center causes a slight increase in the overall cost of RES. This cost eventually decreases to the same level or to a slightly lower level when the new center reaches its full capacity as well. This cyclic effect continues as the scale of the community further increases. Although the highest $\mathrm{LCC} / \mathrm{m} 2$ reduction is achieved at bigger community scales, it's only slightly higher than the already achieved reduction at the scale of one full energy center.

Based on these results, both community density and scale have an impact on the LCC/m2 of technologies implemented in NZE communities. The scale of the community has a significant impact on the reduction of $\mathrm{LCC} / \mathrm{m} 2$, but only up to the point at which the first community-integrated energy center reaches its full capacity. Further increase of community scale only have a minor impact and don't lead to a significantly further $\mathrm{LCC} / \mathrm{m} 2$ reduction. Lower density has a positive impact on the $\mathrm{LCC} / \mathrm{m} 2$ of technologies. The parameter which constrains the maximal rate of energy produced at a community level is the available area for community integrated RES. The LCC/m2 reduction is achieved by the reduced costs of RES integrated at a community level.

\section{French case study}

The second case study chosen for this study is located in Voreppe, a city $15 \mathrm{~km}$ North-West of Grenoble, France. The building in this case study is an apartment building, with a total net area of $1005 \mathrm{~m}^{2}$, and containing 18 dwellings. The climate in Grenoble is warm and temperate, and defined as 'Oceanic' according to the Koppen-Geiger climate classification. The temperatures are highest in July with an average of $20.2{ }^{\circ} \mathrm{C}$ and a peak of around $26.4{ }^{\circ} \mathrm{C}$, and lowest in January with an average of $1.7{ }^{\circ} \mathrm{C}$ and a peak of around $-2.2{ }^{\circ} \mathrm{C}$ (CLIMATEDATA.ORG, n.d.). The scale of the French community that was examined varied from 1 to 28 buildings (i.e. a range of 18-504 dwellings).

In all examined scale and density variations, the optimal combination of technologies identified with the model includes the following technologies:

- Low temperature radiators in each room, which are fed by hot water using the building's hot water distribution system

- A water heating boiler based on bio fuel - wood pallets - integrated at a building or community level.

- A community heat distribution system when a district heating is considered.

- A PV system implemented at a building and/or a community level.

In all cases, the renewable energy production of the heating boiler(s) covers the regulated energy consumption of the community. The difference between the optimal combination of technologies in the various options of density and scale is the level of implementation (building/community) of the heating boiler(s) and the PV systems. As the density and scale of the community increase, the bigger the boiler and the denser the heat distribution system that combine the district heating center, and consequently - the lower its cost. 


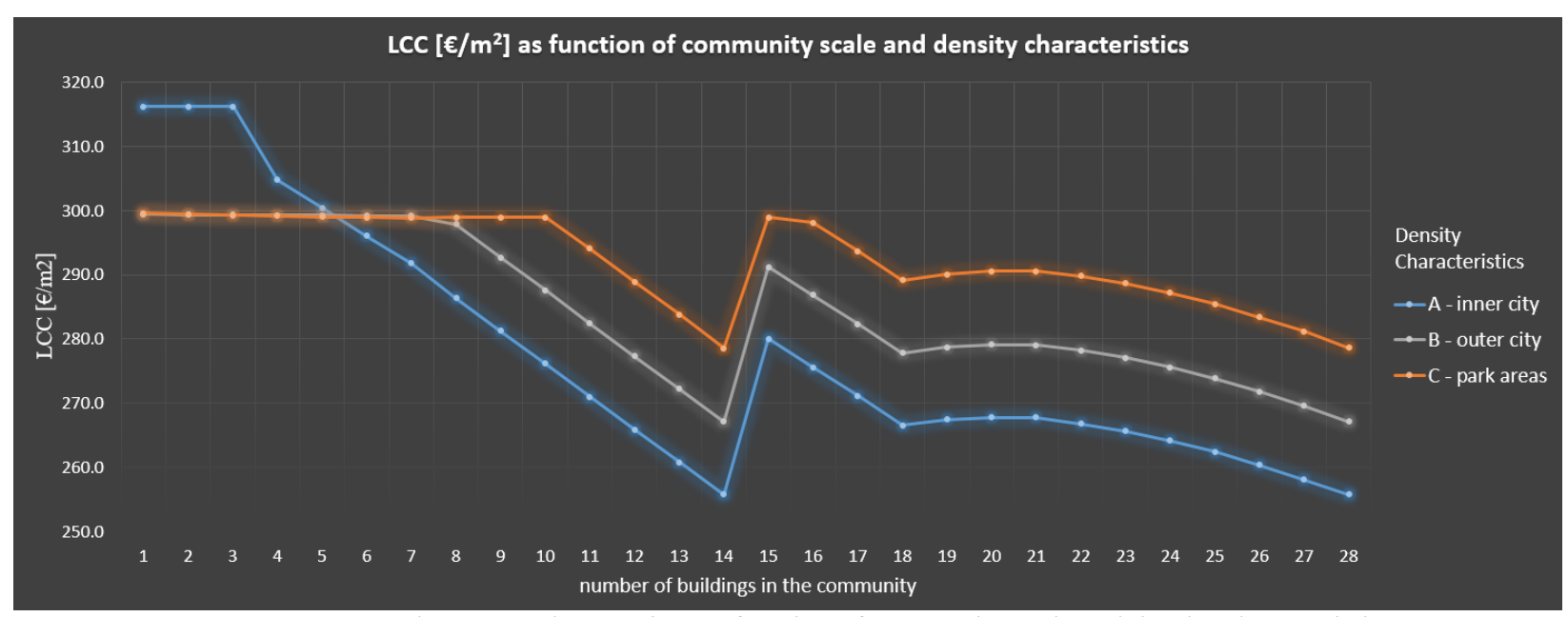

Figure 2: French Case Study, LCC/m2 as function of community scale and density characteristics

As described in Figure 2, the $\mathrm{LCC} / \mathrm{m}^{2}$ of the technologies in a high 'inner city' density at the scale of 5 buildings or lower is significantly higher than in the other two densities. This is explained by the following points:

1. A district heating system is available at a capacity of $0.5 \mathrm{MW}$ and higher, i.e. at least 4 of the buildings that considered in this study. Therefore, the design at the scale of 3 buildings or lower includes only buildingintegrated boilers, which are less cost efficient than district heating.

2. In an 'inner city' density, there is no available area for community-integrated PV systems except on the rooftop of the heating center, which causes an increased $\mathrm{LCC} / \mathrm{m}^{2}$ costs of the PV systems vs. the two other density options.

However, once the community scale increases above 5 buildings the $\mathrm{LCC} / \mathrm{m}^{2}$ is higher in lower densities, and 'inner city' density is $\mathrm{LCC} / \mathrm{m}^{2}$ optimal option out of the three examined. This result is explained by the following:

1. Unlike in the Cypriot case study, in the French case study all the regulated energy, which stands for $\sim 71 \%$ out of the total energy consumption, is produced by the heating system. The PV systems are producing only $\sim 29 \%$ of the total produced renewable energy. Therefore, the heating system has a bigger impact on the $\mathrm{LCC} / \mathrm{m}^{2}$ of the technologies than the PV systems.

2. A district heating system includes a heat distribution system and a heat production boiler. As previously described, the heat distribution system is more cost efficient in a denser environment due to lower capital and heat distribution costs. At the same time, the cost of a heating boiler is decreasing in higher capacities.

Therefore, in higher densities, a district heating system which includes a heat distribution system is more cost efficient than in low densities, which causes an earlier adoption of such system. As more buildings are connected to the system, the costs of the boiler decrease. Therefore, the inclusion of district heating in the optimal design in higher densities occurs in smaller community scales, and the costs keep decreasing as the scale increases. The cost efficiency achieved by the heating system overcomes the low amount of area available for the establishment of community level PV centers. Moreover, some PV centers can be installed on the rooftop of the heating center as previously described, and partially overcome this constraint.

Once the district heating is included in the design, the $\mathrm{LCC} / \mathrm{m}^{2}$ of the technologies decreases as scale grows, and reaches its minimum at the scale of 14 buildings. As the community scale grows further, the $\mathrm{LCC} / \mathrm{m}^{2}$ of the technologies first increases and then decreases again. The reason is similar to the described phenomenon in the Cypriot case study. A scale of 14 buildings requires the establishment of a heating center with a wood pellet boiler at a nearly full capacity of $2 \mathrm{MWp}$, the capacity at which the maximal cost reduction is achieved. Further increase in scale requires the establishment of a new heating center, which is basically a duplication of the achieved technological design. The new heating center won't benefit from the achieved reduced costs of the existing heating center. Therefore, the establishment of a new energy center causes an increase in the overall cost of RES, which eventually reaches the same or slightly lower level when the new center reaches its full capacity as well. This cyclic effect continues as community scale grows further.

Based on the achieved results, the scale of the community has a significant impact on the reduction of $\mathrm{LCC} / \mathrm{m}^{2}$ only up to the point at which the first district heating center reaches its full capacity. Further increase of community scale doesn't provide further significant $\mathrm{LCC} / \mathrm{m}^{2}$ reduction. The $\mathrm{LCC} / \mathrm{m}^{2}$ reduction is achieved by the reduced costs of RES integrated at a community level, in particular the district heating system. This result is in line with the results from the Cypriot case study. It's noteworthy that the increase of community scale above the examined levels in this study would probably result in further $\mathrm{LCC} / \mathrm{m}^{2}$ reduction, due to the integration of high capacity wood chips heating boiler in a district heating center. However, the increasing and then decreasing $\mathrm{LCC} / \mathrm{m}^{2}$ phenomenon would occur at this scale as well, and its technological design would be duplicated, just like in smaller scales examined in this study. As opposed to the results from the Cypriot case study, higher density has a 
positive impact on the $\mathrm{LCC} / \mathrm{m}^{2}$ of technologies at community scales of 6 buildings and higher in the French case study, due to the cost efficiency of the heat distribution system in higher urban densities.

\section{Conclusions}

The results show that both urban density and scale have a direct impact on the $\mathrm{LCC} / \mathrm{m} 2$ of the technologies implemented in NZECs. The $\mathrm{LCC} / \mathrm{m}^{2}$ reduction was achieved through the reduced costs of RES integrated at a community level.

As observed in both case studies, the enlargement of community scale causes a decrease in the $\mathrm{LCC} / \mathrm{m}^{2}$ of the technologies. However, the scale has a significant impact on the $\mathrm{LCC} / \mathrm{m}^{2}$ only up to a certain point. The most significant reduction in $\mathrm{LCC} / \mathrm{m}^{2}$ of the technologies is achieved at a scale at which the first feasible energy center reaches its full possible capacity. Although the lowest $\mathrm{LCC} / \mathrm{m}^{2}$ is achieved at bigger community scales, it's only slightly lower than the already achieved cost at the scale of one full energy center. The reason for this phenomenon is the assumption that the cost of RES per unit or $\mathrm{kWp}$ is decreasing as the total capacity of the installation is increasing. The assumption is valid for each installation by itself, which is in this case - each energy center. Further increase of scale requires the establishment of a new energy center, or in other words, a duplication of the achieved technological design. The RES installed in the new energy center doesn't benefit from the reduced costs achieved in the existing energy center. Therefore, the establishment of a new energy center causes a slight increase in the overall cost of RES, which eventually reach the same or slightly lower level when the new center reaches its full capacity as well. This cyclic effect continues as community scale grows further.

Considering the above, we suggest that the increase in community scale causes a decrease in the $\mathrm{LCC} / \mathrm{m} 2$ of the implemented technologies, however, the cost reduction is highly constrained by the size of the largest energy center of the community.

Unlike the scale of the community, urban density had an opposite impact on the $\mathrm{LCC} / \mathrm{m} 2$ of the technologies in the two case studies. While in the Cypriot case study lower density caused a reduction in the $\mathrm{LCC} / \mathrm{m}^{2}$ of the technologies, in the French case study the reduction was achieved as urban density increased. The difference is related to the local climate and the required energy to supply the HVAC \& WH demand of the communities. The community in the Cypriot case study is located in a warm climate, and all of its energy requirements can be supplied by electricity. Therefore, $95 \%$ of the energy in this case study was supplied by PV systems, whose installations are known to require space. Consequently, as density decreased, more and bigger community-integrated PV centers could be installed, which resulted in lower costs. The parameter of the available area for communityintegrated RES had an impact not only on the absolute value of the $\mathrm{LCC} / \mathrm{m}^{2}$ reduction, but also on the rate (in terms of community scale growth) at which this reduction was achieved. It's noteworthy that the impact of density is limited by the following constraints:

1. Energy production regulations, which make overproduction cost inefficient, as showed in the results of this study.

2. The assumption that very low urban density with very big energy centers would require intensive investments in the local electrical grid, which would negatively balance the cost reduction.

Unlike the Cypriot case study, the French case study is located in a colder climate, and all of its regulated energy is supplied by a heating system. As described earlier in this work:

1. The cost of heat distribution has a significant impact on the overall cost of the technologies in this case study

2. Heat distribution cost is decreasing as urban density is increasing

3. It's assumed that the heat production centers are located on the outskirts of the settlement and aren't constrained by lack of land in high densities

Therefore, the increased urban density of the French case study resulted in lower $\mathrm{LCC} / \mathrm{m}^{2}$ of the technologies. It's noteworthy that we assume that the positive impact of high density is limited due to the fact that:

- The design and construction of a heat distribution infrastructure in very high densities is physically complicated and capital intensive

- The lack of space may affect the effectiveness of other required technologies

Considering the above, we suggest that the impact of urban density on the LCC/m2 of the technologies depends on the local climate and the energy types required to meet the regulated energy demand of the community. Low urban density has a positive impact on the $\mathrm{LCC} / \mathrm{m} 2$ in communities with electricity-based demand, while high urban density has a positive impact in communities with heat-based demand. In both cases, the effect of urban density on the LCC/m2 of the technologies is limited due to renewable energy production regulations and energy distribution limitations.

The current workflow of urban planning, in which the technological design is performed only after the urban density, the unbuilt areas and the types of the buildings are already set, is constraining the type of the technologies that can be implemented and the energetic and financial efficiency that can be achieved. Following the presented results of density and scale implications on the $\mathrm{LCC} / \mathrm{m} 2$ of the technologies, we suggest that the consideration of the technological design is critical in the first stage of urban planning of energy efficient communities. The consideration of the technological design before the urban density, the unbuilt areas and the building types are set will contribute to a better definition of these parameters and assist to achieve better energetic and financial efficiency of Net or nearly Zero Energy Communities. 
This is a first attempt to study the economic implications for urban planning of an implementation of the NZE approach at a settlement level. Further research is needed to gain a better understanding of this topic. Such research could include a relaxation of the assumptions that were made in this research, such as the uniform distribution of buildings, and the equal capacity of energy centers. Additional building types, locations and climates could also be considered.

\section{References}

Allegrini, J., Orehounig, K., Mavromatidis, G., Ruesch, F., Dorer, V., \& Evins, R. (2015). A review of modelling approaches and tools for the simulation of district-scale energy systems. Renewable and Sustainable Energy Reviews, 52, 1391-1404. https://doi.org/10.1016/j.rser.2015.07.123

Carlisle, N., Geet, O. Van, \& Pless, S. (2009). Definition of a "Zero Net Energy" Community. Retrieved from https://www.nrel.gov/docs/fy10osti/46065.pdf

CLIMATE-DATA.ORG. (n.d.). Climate Grenoble: Temperature, Climograph, Climate table for Grenoble - Climate-Data.org. Retrieved June 24, 2018, from https://en.climate-data.org/location/357/

DeBaillie, L. (2012). Community and Multi-building Development's Key Role in a Net-zero Energy Future. Strategic Planning for Energy and the Environment, 32(2), 21-31. https://doi.org/10.1080/10485236.2012.10554232

Fu, R., Chung, D., Lowder, T., Feldman, D., Ardani, K., Fu, R., ... Ardani, K. (2016). U.S. Solar Photovoltaic System Cost Benchmark: Q1 2016. National Renewable Energy Laboratory, (September), 37. https://doi.org/10.7799/1325002

Fuller, S., \& Petersen, S. (1996). Life-Cycle Costing Manual for the Federal Energy Management Program. 1995th Ed. Washington DC: U.S. Department Energy. Retrieved from https://ws680.nist.gov/publication/get_pdf.cfm?pub _id $=907459$

Hamdy, M., Hasan, A., \& Siren, K. (2013). A multi-stage optimization method for cost-optimal and nearlyzero-energy building solutions in line with the EPBD-recast 2010. Energy and Buildings, 56, 189203. https://doi.org/10.1016/j.enbuild.2012.08.023

Marique, A.-F., \& Reiter, S. (2014). A simplified framework to assess the feasibility of zero-energy at the neighbourhood/community scale. Energy and Buildings, 82 , 114-122. https://doi.org/10.1016/J.ENBUILD.2014.07.006

Marszal, A. J., \& Heiselberg, P. (2011). Life cycle cost analysis of a multi-storey residential Net Zero Energy Building in Denmark. Energy, 36(9), 56005609. https://doi.org/10.1016/j.energy.2011.07.010

Marszal, A. J., Heiselberg, P., Lund Jensen, R., \& Nørgaard, J. (2012). On-site or off-site renewable energy supply options? Life cycle cost analysis of a Net Zero Energy Building in Denmark. Renewable Energy, 44, 154-165. https://doi.org/10.1016/j.renene.2012.01.079

Moran, P., Goggins, J., \& Hajdukiewicz, M. (2017). Super-insulate or use renewable technology? Life cycle cost, energy and global warming potential analysis of nearly zero energy buildings (NZEB) in a temperate oceanic climate. Energy and Buildings, 139(2017),

590-607. https://doi.org/10.1016/j.enbuild.2017.01.029

Orehounig, K., Evins, R., \& Dorer, V. (2015). Integration of decentralized energy systems in neighbourhoods using the energy hub approach. Applied Energy, 154 , 277-289. https://doi.org/10.1016/j.apenergy.2015.04.114

Voss, K., Musall, E., \& Lichtmeß, M. (2011). From LowEnergy to Net Zero-Energy Buildings: Status and Perspectives. Journal of Green Building, 6(1), 4657. https://doi.org/10.3992/jgb.6.1.46

Young, C. (2018). Excel Solver: Which Solving Method Should I Choose? | EngineerExcel. Retrieved June 15, 2018, from http://www.engineerexcel.com/excel-solversolving-method-choose/

Zakis, K., Zakis, V., \& Arfridsson, J. (2016). Eleven Nearly Zero New Building Life Cycle Cost and Dynamic Performance Optimization by Computer Modeling in Cold Climate. Procedia Computer Science, 104(December 2016), 302-312. https://doi.org/10.1016/j.procs.2017.01.139 